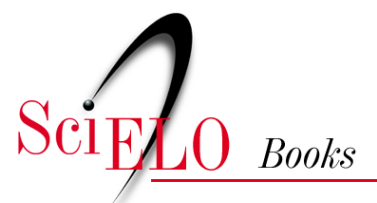

\title{
Prefácio
}

\section{Sergio Rego}

\section{SciELO Books / SciELO Livros / SciELO Libros}

REGO, S. Prefácio. In: SHRAMM, F. R. Três ensaios de bioética [online]. Rio de Janeiro: Editora FIOCRUZ, 2015, pp. 7-9. ISBN: 978-85-7541-586-3. https://doi.org/10.7476/9788575415863.0001.

(c) ()

All the contents of this work, except where otherwise noted, is licensed under a Creative Commons Attribution 4.0 International license.

Todo o conteúdo deste trabalho, exceto quando houver ressalva, é publicado sob a licença Creative Commons Atribição 4.0. 


\section{Prefácio}

A história da bioética no Brasil está indelevelmente escrita com o nome de alguns ilustres precursores, e Fermin Roland Schramm tem o seu registrado em qualquer versão que se escreva. Formado em linguística pela Universidade de Genebra, na Suíça, completou seu mestrado em semiótica na École des Hautes Études en Sciences Sociales em 1978 na França e doutorou-se em saúde pública na Escola Nacional de Saúde Pública da Fiocruz em 1993. Realizou seu pós-doutorado em bioética na Universidade do Chile. Pensador original, rigoroso no método e nos conceitos, Schramm tem sua trajetória acadêmica marcada em sua produção científica, bem como a sua compreensão da vida social e política de nossos tempos. Tendo o olhar sanitarista e a busca pela justiça como compromisso político e social, propôs a incorporação da proteção de indivíduos e populações vulneradas como uma das tarefas da bioética e em seu fundamento.

Mais do que um pensador que contribui para o desenvolvimento da bioética no Brasil, Roland é uma das lideranças acadêmicas que procuram fomentar uma reflexão em bioética original no âmbito da América Latina. Entendendo, como não podia deixar de ser, que as contribuições originárias de pensadores de alhures não devem ser desconsideradas, Roland se insere no debate filosófico sobre os fundamentos e a aplicação das teorias no contexto latinoamericano. Sua formação e sua prática enfatizam o debate no campo teórico e não no meramente ideológico, o que não afasta a ação política, mas a qualifica. O presente livro, Três Ensaios de Bioética, insere-se nesse contexto, e é uma contribuição significativa para todos que estejam comprometidos com o desenvolvimento teórico da bioética e, como não poderia deixar de ser, em sua aplicação na solução dos conflitos morais.

O professor Schramm foi, de 1997 até 2014, consultor em bioética do Instituto Nacional do Câncer no Rio de Janeiro, onde criou e coordenou o Conselho de Bioética. Nesse período teve a oportunidade de se aproximar do processo clínico, o que o levou a uma experiência concreta de debate com os 
profissionais da saúde envolvidos no cuidado em um hospital especializado. Para além da discussão geral da formulação política e das decisões mais próximas do campo da saúde pública, incorporou a experiência de conduzir seminários sobre oncologia pediátrica e cuidados paliativos.

Vejo o primeiro ensaio deste livro como um reflexo dessa experiência: como avaliar as situações relacionadas com a chamada bioética clínica, ou seja, com o cuidado individualizado de pacientes? Trata-se, aqui, de discutir não um método para a solução dos problemas morais, mas a possibilidade, e sua eventual importância, da análise criteriosa de conceitos. Schramm absorve a tarefa da filosofia analítica sem deixar dúvidas de que vê na bioética "a superação da tradicional oposição entre as vertentes analítica e continental em filosofia". Àqueles familiarizados com a contribuição teórica de Schramm, esse ensaio fundamenta teoricamente o que é tão característico em sua produção acadêmica: o cuidado com a precisão dos conceitos e com a análise estrita dos fatos e argumentos relacionados, aqui aplicados à reflexão sobre a pertinência de se pensar em uma metabioética clínica realista.

Os dois ensaios que completam a obra se caracterizam pelo mesmo cuidado analítico e com a precisão conceitual e metodológica. Um deles, o segundo, aborda a moralidade da genômica. Tema atual e dos mais relevantes para a análise bioética, é discutido por Schramm com uma abordagem que contempla a identificação dos argumentos favoráveis e contrários à engenharia genética. Entendo que embora sejamos contemporâneos de um grande avanço no conhecimento genético e em sua aplicação para pesquisas e na clínica, esse conhecimento ainda parece aterrorizar segmentos significativos de nossa sociedade, que ainda se preocupam com a possibilidade de que certas práticas, aceitas para animais não humanos e vegetais, sejam aplicadas a seres humanos. Esse temor é, de fato, inibidor do debate, mas não do desenvolvimento técnico e tecnológico. Nesse ensaio, Schramm traz fatos e argumentos para o foco da atenção dos leitores, contribuindo para o desenvolvimento do raciocínio crítico e sem preconceitos sobre o tema.

Trabalho semelhante é feito no terceiro ensaio, intitulado "Bioética 'e/ ou' biossegurança: uma possível interface na avaliação e gestão da prática da biotecnociência?", em que Schramm discute a interface entre bioética e 
biossegurança em um contexto social em que o risco produzido é inerente ao desenvolvimento da sociedade moderna. Mais uma vez o autor se utilizará da etapa de elucidação conceitual como condição indispensável para que a análise crítica seja feita de forma imparcial, distinguindo os conceitos de risco, perigo e dano, para então apresentar e discutir as possibilidades teóricas de enfrentamento dos problemas morais relacionados.

O privilégio de escrever este prefácio e oferecer ao leitor alguns elementos adicionais para a compreensão destes ensaios é ainda mais especial para mim, que tive também o privilégio de ter o professor Roland como orientador no meu processo de doutoramento e com ele conviver no Programa de Pós-Graduação em Bioética, Ética Aplicada e Saúde Coletiva, programa que, de forma inédita e inovadora no campo da bioética, associou as principais instituições de ensino superior do estado do Rio de Janeiro: Universidade Federal do Rio de Janeiro, Universidade Federal Fluminense, Universidade do Estado do Rio de Janeiro e Escola Nacional de Saúde Pública da Fiocruz.

Com muita frequência as pessoas que cumprem o papel de prefaciar um livro falam de quão indispensável o livro em questão é, para tal ou qual população. Sem querer cair no lugar-comum, gostaria de salientar que este segundo livro autoral de Fermin Roland Schramm, pesquisador com quase duzentos trabalhos publicados, preferencialmente em periódicos científicos, representa o início do pagamento de uma dívida para com a comunidade acadêmica dedicada ao estudo da bioética, pois em um livro o autor se vê liberto das limitações impostas pelos periódicos em relação ao número de páginas e mesmo de referências. Temos neste livro, ainda que organizado como a reunião de três ensaios, acesso aos fundamentos teóricos com os quais o autor debate para construir suas formulações. Que este seja o primeiro de uma série de textos em que Schramm possa dialogar mais amplamente com os autores referenciados, propiciando a mais ampla compreensão de sua trajetória analítica aos seus leitores.

Sergio Rego

Pesquisador titular da Escola Nacional de Saúde Pública Sergio Arouca/Fundação Oswaldo Cruz 